\title{
Use of the Graphic Tablet in the Art and Educational University
}

\author{
Almaz Omorkulov'1, Abdibali Maripov', Mamyraly Eshbaev¹, Kasymbek Shakirov², \\ Tazagul Alieva1, Erkingul Toktorbaeva ${ }^{3}$, Tamara Kadyrbaeva1, Zhypargul Abdullaeva ${ }^{4 *}$ (i)
}

${ }^{1}$ Department of Drawing, Sketching and Labor, Faculty of Arts, Osh State University, Osh, Kyrgyzstan

${ }^{2}$ Department of Theory and Methodic of Secondary Special Education, Osh State University, Osh, Kyrgyzstan

${ }^{3}$ Department of Light Industry Technology, Osh Technological University, Osh, Kyrgyzstan

${ }^{4}$ Science and Research Department, Osh State University, Osh, Kyrgyzstan

Email: *jypar.science@oshsu.kg

How to cite this paper: Omorkulov, A., Maripov, A., Eshbaev, M., Shakirov, K., Alieva, T., Toktorbaeva, E., Kadyrbaeva, T., \& Abdullaeva, Z. (2021). Use of the Graphic Tablet in the Art and Educational University. Art and Design Review, 9, 19-26. https://doi.org/10.4236/adr.2021.91002

Received: November 10, 2020

Accepted: January 11, 2021

Published: January 14, 2021

Copyright $\odot 2021$ by author(s) and Scientific Research Publishing Inc. This work is licensed under the Creative Commons Attribution International License (CC BY 4.0).

http://creativecommons.org/licenses/by/4.0/

\section{(c) (i) Open Access}

\begin{abstract}
This article is discussing application of graphic tablet in the art educational University, by introducing it in design and work with graphical images related to the creation and editing of raster, vector graphics. Sequential drawing of the simplest elements for training the hand's muscle memory achieved during classes by use of the pen and graphic tablet. The relevance in the application of this device opens up new opportunities in art education when using modern graphic technologies. The main findings observed at the end of the class, where students familiarized themselves with the principles of connection and using the technique of pen (stylus) on the graphics tablet. Students mastered the techniques of drawing from the simplest elements to more complex tasks. The article discusses the practical use of a graphics tablet in modern art education in the context of distant learning.
\end{abstract}

\section{Keywords}

Graphic Tablet, Electronic Pen (Stylus), Device, Graphic Arts, Digitizer, Multimedia

\section{Introduction}

Smart mobile devices and tablets are the most recent addition to the technological innovations supporting and enhancing the teaching with learning processes (Tamim et al., 2015; Ditzler et al., 2016). In particular, specialized multimedia tools are of great interest, the main purpose of which is to increase the efficiency of training and innovative development. These modern tools include interactive 
whiteboards, a graphic tablet (digitizer) (Wollscheid et al., 2016), speech and visual input devices, and web cameras. A graphics tablet can be considered as the most convenient and effective tool; as integrating computer-based technology into teaching and learning influences student engagement within higher education settings (Schindler et al., 2017). A graphics tablet (from English, means graphics tablet or graphics pad, drawing tablet, digitizing tablet, digitizer-digitizer, and digitizer) is a device for entering drawings by hand directly into a computer.

At the present, the main task of a teacher is to interest students with innovative format during the educational process. One of the innovations in the use of modern graphic technologies, such as a graphic tablet, certainly shows the student's interest in the educational process. The introduction of innovative technologies in art educational universities of modern graphic technologies is an important factor for students' aesthetic and moral education, which plays an important role in the formation of creative skills. The novelty means the use of graphic technologies in the art educational universities, as innovation will interest the modern audience (Grebennikov, 2002).

However, disadvantages in the use of mobile devices should be taken into account due to student's distraction and the continuous evolution of technology, which is making resources obsolete in a short time (Ricoy \& Sánchez-Martínez, 2019). During the use of a graphics tablet, minor difficulties were identified among students. Students, in the process of mastering drawing on the tablet, uncertainly hold the pen (stylus) in their hands, since the thickness of pen is slightly larger compared to a regular pencil when gripped with the fingers. When drawing on the tablet screen, students need to constantly look at the monitor screen, controlling the result of their works. In general, mastering of the drawing skills on a graphics tablet at the initial stages always causes inconveniences, which requires students' persistence.

Even art is often seen as a separate area from science, the drawing can be a valuable way to deepen students' understanding of a subject (Owens, 2018). Drawing with a digital pen might foster alternative forms of collaborative creativity (Sakr, 2018). Our task was to draw a sketch model using a graphic tablet during the art education class. The sketch itself was drawn on paper with paints or gouache. Further, according to the drawn sketch, students acquire the necessary fabrics of the material, taking into account the color and type of material. The sketch on the drawing gives a complete picture of how the finished model will look like.

When making any garments, the designer has to implement future sketches on paper with a tasteful creative idea. The main task at an art educational university is to train design fashion designers who can develop sketches of their ideas not only on paper but also on a graphic tablet. Students of art and education universities must be able to draw well to convey their idea, no matter how vivid it may be in his or her imagination. In general, the figure of the model in the sketch of the drawing should look as thin, elongated, and graceful as possible, so future fashion designers should depict the waist of the model as thinner 
than the arms, and the legs are twice as long as the body. In addition, when drawing a model on a graphics tablet, students need to observe the measure and maintain a certain balance.

\section{Research Tools}

Graphic tablet devices, wireless pen (stylus), laptop computers, screen set in this art education class. On the sketch of the drawing, it is important to take into account the main folds of the clothes, since any fabric tends to drape, without taking into account such details, the drawing will look unnatural. Using a graphics tablet, the drawn sketch helps to think through all the details of the future product, both in color and in the full volume of the outline of the figure.

So what is the graphics tablet that is gaining popularity in the creative community? Let us take a closer look: the modern market produces graphic tablets of various functionality, both by the manufacturer and by model range. The general task of this device is to replace the classic mouse with a more convenient wireless, electronic pen. The set includes a wireless pen (stylus), a flat tablet with a sensitive screen, an installation program (driver), and a USB cable. The pen kit also comes with several different rod thicknesses to provide more benefits for the task.

The screen itself is sensitive when approaching and touching the pen. Some models may include a dedicated mouse to manipulate any different actions on the monitor screen (Figure 1).

The complete set of this device consists of a pen (stylus) that looks like a thick pencil and the device itself in the form of a flat tablet with a screen. Modern graphic tablets allow you to perform a wide range of manipulations when performing certain tasks. For example, control the operation of the computer on the monitor, work with three-dimensional models, draw freehand with a pen, edit color and black-and-white photographs, process computer graphics, draw pictures, write various texts in editors, use keyboard shortcuts to perform versatile programmed actions, and much more. As a result, given its capabilities discussed above, we can safely say that this device (graphic tablet) justifiably performs a wide range of tasks.

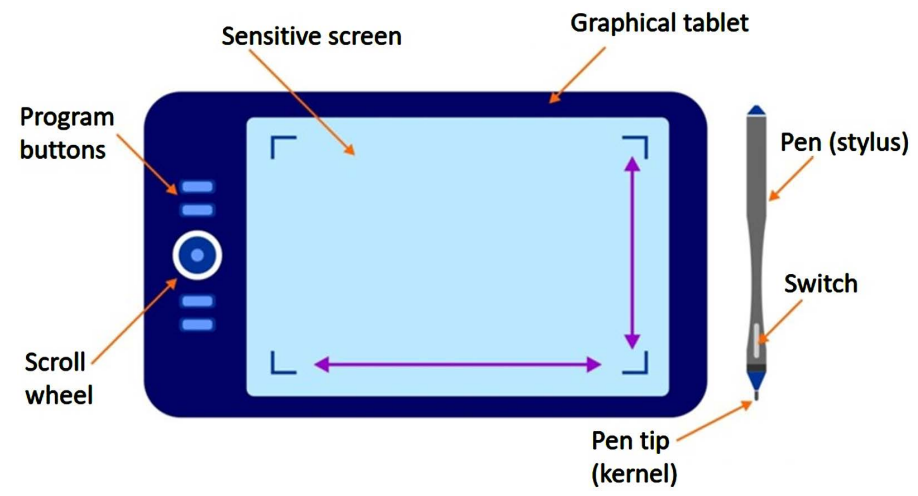

Figure 1. Graphic tablet device used in this class. 
One of the innovations of using this device is the use of a graphics tablet in art and educational institutions. The introduction of a graphics tablet in art educational universities is a kind of step towards creative and innovative methods of teaching art direction. Students of universities, using this tablet, can reveal completely new possibilities in creative activity. With the help of this device, students master completely new methods and possibilities in the visual arts. Consider some of the convenience of this device.

Firstly, the convenience of using an electronic pen with various graphics programs for working with graphics, such as CorelDraw, Photoshop, Adobe Illustrator, Corel painter. Additionally, using the stylus, instead of the classic mouse, you can manipulate various actions on the monitor screen, such as opening and closing windows, minimizing, dragging, copying, etc.

Second, the cordless pen achieves greater precision when drawing vector drawings or manipulating photographic images. Bright and rich colors are expressed. The initial process of mastering drawing undoubtedly arouses interest and curiosity, which will take some time to confidently master the electronic pen. In general, a graphic tablet is an electronic sheet of paper and a wireless electronic pen (stylus) that allows you to perform any manipulations on the computer screen, which makes it convenient to work with all known applications.

To work, students need to connect the tablet to the computer via a wired USB port and then install the installation disk of the program (driver) as a result, the tablet can be used for work. When drawing on a tablet, when the pen touches the sensitive screen, the participant sees the immediate result of the drawing on the screen. The pen, while drawing on the screen, can change the thickness of the lines depending on the tilt and pressing of the stylus.

By holding the pen in student's hands, they can apply pressure to adjust the pressure level of the pen, creating a different thickness of the brushstroke, from thinner to thicker. Since the pen is sensitive to pressure on the screen, when you press firmly on the pen, the line thickness thickens and decreases in the opposite order with weak pressure.

If you approach this objectively, you can consider the positive aspects of using a graphics tablet:

1) An electronic tablet completely replaces a conventional mouse when working on a computer, while allowing you to more quickly and accurately perform any navigation functions and tasks.

2) Sketching graphs, complex and detailed figures, etc.

3) Using a color palette which in turn gives clarity to the drawings.

4) Use of ready-made drawings (color).

5) Hygiene in the classroom is not required during class using chalk and rags.

6) Saving paper (from deforestation).

7) Convenient to carry with you, due to its small size and weight.

For better results, it will undoubtedly take some time for your hand to get used to the tablet. While drawing, do not overextend your hand, squeezing the 
pen with all your strength, but, on the contrary, soften the holding of the pen and smoothly draw a trail of lines. The line thickness of the drawing changes as the pen is tilted vertically and horizontally. Most importantly, in the early stages of mastering drawing on a graphics tablet, this repeated repetition of drawing elementary simple lines concludes the key point. Daily arm training leads to muscle memory, which is important for mastering drawing on a tablet.

For better results, it will undoubtedly take some time for your hand to get used to the tablet. While drawing, do not overextend your hand, squeezing the pen with all your strength, but, on the contrary, soften the holding of the pen and smoothly draw a trail of lines. The line thickness of the drawing changes as the pen tilted vertically and horizontally. Most importantly, in the early stages of mastering drawing on a graphics tablet, this repeated repetition of drawing elementary simple lines concludes the key point. Daily arm training leads to muscle memory, which is important for mastering drawing on a tablet.

\section{Class Organization}

For classes with familiarization and practical use of a graphics tablet, computer audiences provided, in the first media class for lectures there is an interactive board with a projector, a graphics tablet connected to a laptop (Figure 2). During the lecture, the teacher demonstratively draws on a graphic tablet, looking at the laptop monitor, while students see the process on the interactive whiteboard screen. Memorize and write down the lecture notes in a notebook.

A lecture class equipped with a projector, interactive whiteboard, and laptop with a graphics tablet is shown in Figure 2. In the second computer class, ten computers with technical specifications for working with graphics are equipped (Figure 3).

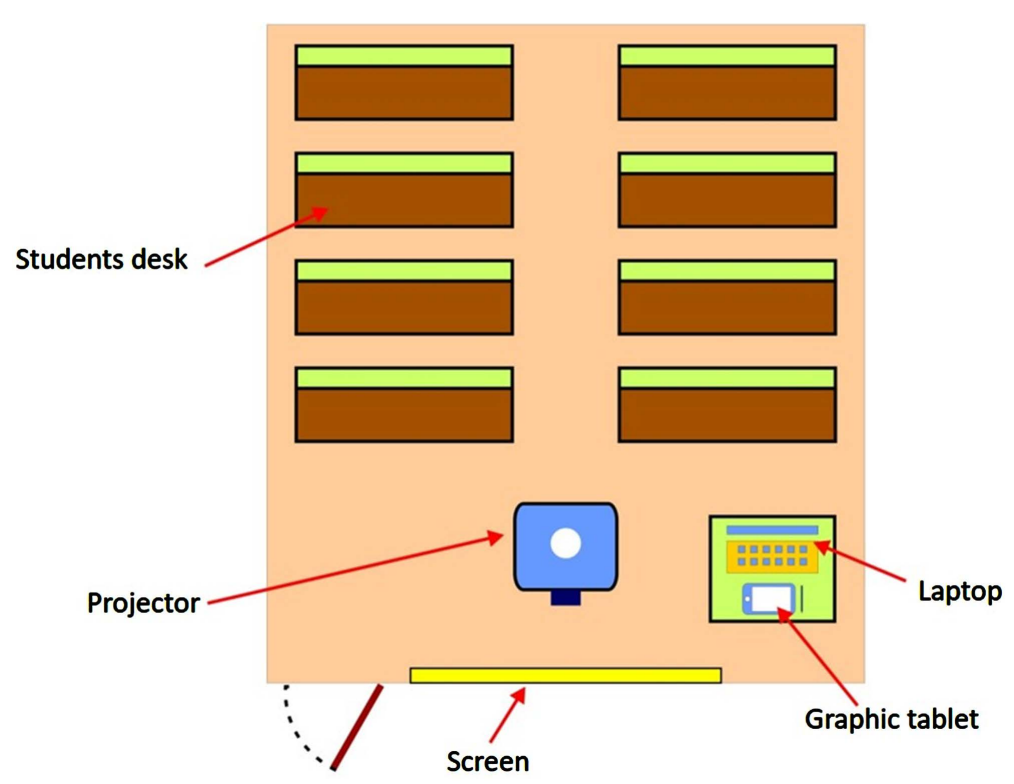

Figure 2. Class equipped with projector, interactive whiteboard, laptop and a graphic tablet. 


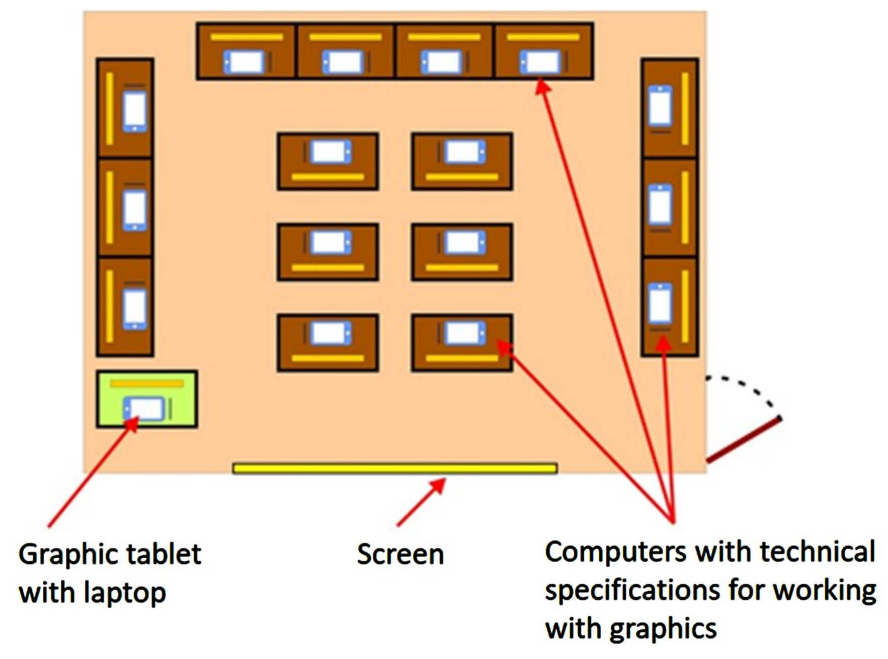

Figure 3. Computer class equipped with technical specifications.

During computer graphics class, practice shows good indicators of students attendance due to the fact that the current generation is showing great interest in the latest technologies at the present time. Students actively use modern gadgets and software both in mobile devices and in desktop computers, which is possible with the use of a graphics tablet. The results of class attendance show that $80 \%$ $85 \%$ of students actively attend classes out of $100 \%$ students. From $80 \%$ percent of students at the initial stage of the lessons, $25 \%$ - 30\% quickly master the technique of drawing on a graphics tablet, which in general gives good indicators of student activity. Remaining $60 \%-70 \%$ of students also master the technique of drawing on a graphics tablet with a small margin.

The computers have graphics packages Adobe Photoshop, CorelDraw, Adobe Illustrator. In the computer class, students directly carry out in practice the demonstration lesson studied in the lecture class. Computer configuration parameters during class were in Table 1.

\section{Students Skills Developed during Class}

Using the example of the first lesson, we will draw many points on the screen for further connection into one whole line. In the first exercise, students learn:

- Control the direction of the lines

- Smoothly change pen direction

- Trains the arm in various positions

- Smooth connection of lines

- RGB colors

To consolidate the lesson, students scan a sketch of the model for its further processing on a graphics tablet. Firstly, paint over the model in color using a graphics tablet, then outline the outline of the drawing with an outline. In this task, students need initially to paint over all parts of the shape, clothes of the scanned drawing in color as it is. Next, you need to circle the whole figure with a dark outline. 
Table 1. Devise types and names used during this class.

\begin{tabular}{cc}
\hline Devise type & Name \\
\hline Processor & Intel (R) Core (TM) i5-4590 CPU 3.30 GHz \\
System type & x64-based \\
Operative memory & DDR3 8 GB \\
Video card & NVIDIA GeForce GT 1030
\end{tabular}

In the process of completing simple tasks on the tablet, students gradually master the skills of drawing and possession of an electronic pen. Initially, students performed the simplest tasks in drawing elementary figures. In simple exercises, the muscle memory of the hand remembers the various inclinations of the stylus with its results, which makes it possible to perform more and more complex drawing tasks in the future. In the next task of the lesson, students will have to paint over the shape of the model by the simplest painting of the shape in color, and then all parts of the drawing outlined with a dark outline of the shape of the model.

The goal of this lesson was to master the drawing of the simplest elements of shapes using an electronic pen on a tablet. Development of muscle memory in the hands using various pen tools. Students, when mastering a graphics tablet, master the new capabilities of this device, revealing new possibilities for the creative process. Additional skills developed in this class are students basic, artistic and graphical drawing skills, convenience of the scanned graphic drawing digitization with subsequent mounting directly on the monitor screen allow students more opportunities in use of this device.

\section{Conclusion}

It is necessary to use modern technologies in art education classes. Students did not just draw and painted on paper but mastered new drawing methods in various graphic editors by using a tablet. The practical importance of this work is the solution to problems in distant learning and the application of a graphic tablet for drawing. Students learn and develop skills for a new style of drawing approaches not only on plain paper but on a flat electronic tablet device. University students discover new opportunities for creativity in the use of a graphics tablet in the field of computer graphics. Thus, the introduction of this device in art educational universities opens up new opportunities in the field of creativity, revealing completely new teaching methods.

\section{Conflicts of Interest}

The authors declare no conflicts of interest regarding the publication of this paper.

\section{References}

Ditzler, C., Hong, E., \& Strudler, N. (2016). How Tablets Are Utilized in the Classroom. 
Journal of Research on Technology in Education, 48, 181-193.

https://doi.org/10.1080/15391523.2016.1172444

Grebennikov, K. A. (2002). Computer Graphics as a Means of Professional Training of Design Specialists (195 p). Dissertation, Voronezh.

Owens, B. (2018). Science and Technology Education. Nature Outlook, 562, S1. https://doi.org/10.1038/d41586-018-06829-9

Ricoy, M. C., \& Sánchez-Martínez, C. (2019). Tablet Use in Primary Education. Technology, Pedagogy and Education, 28, 301-316. https://doi.org/10.1080/1475939X.2019.1608291

Sakr, M. (2018). Multimodal Participation Frameworks during Young Children's Collaborative Drawing on Paper and on the iPad. Thinking Skills and Creativity, 29, 1-11. https://doi.org/10.1016/j.tsc.2018.05.004

Schindler, L. A., Burkholder, G. J., Morad, O. A., \& Marsh, C. (2017). Computer-Based Technology and Student Engagement: A Critical Review of the Literature. International Journal of Educational Technology in Higher Education, 14, 1-30. https://doi.org/10.1186/s41239-017-0063-0

Tamim, R., Pickup, D., Borokhovski, E., Bernard, R. M., \& Saadi, L. (2015). Tablets for Teaching and Learning: A Systematic Review and Meta-Analysis (63 p). Common Wealth Learning.

Wollscheid, S., Sjaastad, J., \& Tømte, C. (2016). The Impact of Digital Devices vs. Pen(cil) and Paper on Primary School Students' Writing Skills-A Research Review. Computers \& Education, 95, 19-35. https://doi.org/10.1016/j.compedu.2015.12.001 